\title{
A MULTI CRITERIA APPROACH FOR ENERGY RECOVERY FROM SOLID MUNICIPAL WASTE
}

\author{
Alexander Voronov ${ }^{l}$ \\ Maria Belova ${ }^{2}$ \\ ${ }^{I}$ St. Petersburg State University of Engineering and Economics, Russia \\ ${ }^{2}$ St. Petersburg State University for Economics and Finance, Russia
}

\begin{abstract}
The paper presented describes an original technique for decision making regarding solid waste management systems design including the process of choice for its complexity, location and economic aspects as well as the multi criterion model for energy recovery of waste. The mathematical model is worked out for the process of decision making upon the system and process design which makes it to a certain extend a universal solution. The study of the economic and environmental aspects of the energy recovery of waste is also provided in the paper. It includes analysis of the investments' effectiveness based on certain indexes. In this part again the original formulas are used for calculation and providing the data for decision making upon the expenditures needed.
\end{abstract}

\section{KEY WORDS}

Multi-criterion analysis; Waste management; Energy recovery; Iindicators for sustainable development

\section{INTRODUCTION}

The peculiarity of the solid waste management (SWM), let it be in industrialized or developing country, megalopolis or small town, is the complexity and sometimes even conflict of the aspects to be taken into account in the process of decision making. Especially difficult to manage this task is nowadays, when the sustainable development principles determine the priorities and, on the other hand, the legislative restrictions get only stricter while the financial base stays limited.

The multi criteria analysis methods comply better than others when dealing with the decision making in the field of the waste management. In the following study the optimal model for the waste management system is presented with a further analysis of its unit for energy recovery from the solid municipal waste (SMW) using a multi criteria approach. The objective in this case is to minimize cost and risk by optimizing the fuel composition and its ecological damage. The results of the study, in particular, are to be used for the purposes of reform and development of the SWM system in St. Petersburg, Russia. 


\section{BACKGROUND}

Being industrial, touristic and trade center of the Northwest Russia, St. Petersburg produces at least nine million cubic meters of the solid municipal waste per year with a further growth tendency. Only five percent of this amount is recycled. The rest of the waste is disposed to the one of the four landfills or ends up at the numerous dump areas around the city.

The fact of the critical state of the solid waste management in St. Petersburg is recognized by the city authorities and the necessity of the measures to be taken is clear. At the moment, there is a number of the consolidated programs, aiming to improve the current situation in the solid waste management of the Russian second largest city. The option of the energy recovery from the solid municipal waste is among the most promising efforts mentioned.

The Figure 1 represents the systems and processes in St. Petersburg, including current practice (GREY) and prospective development (BLUE). The system presents a balanced usage of the different waste utilization techniques, including energy recovery, aiming to provide effective and stable model for the SWM in St. Petersburg.

This model was developed based on the indicators for sustainable development as the criteria, with their environmental, economic, social and institutional components [1]. Such approach creates innovative and productive management technique to assess the alternative schemes at decision making. The approach proved to be feasible also to create the structure with the effective capabilities for assessment and supervision of the projects in the field under discussion and meeting the key priorities of the territory sustainable development [2].

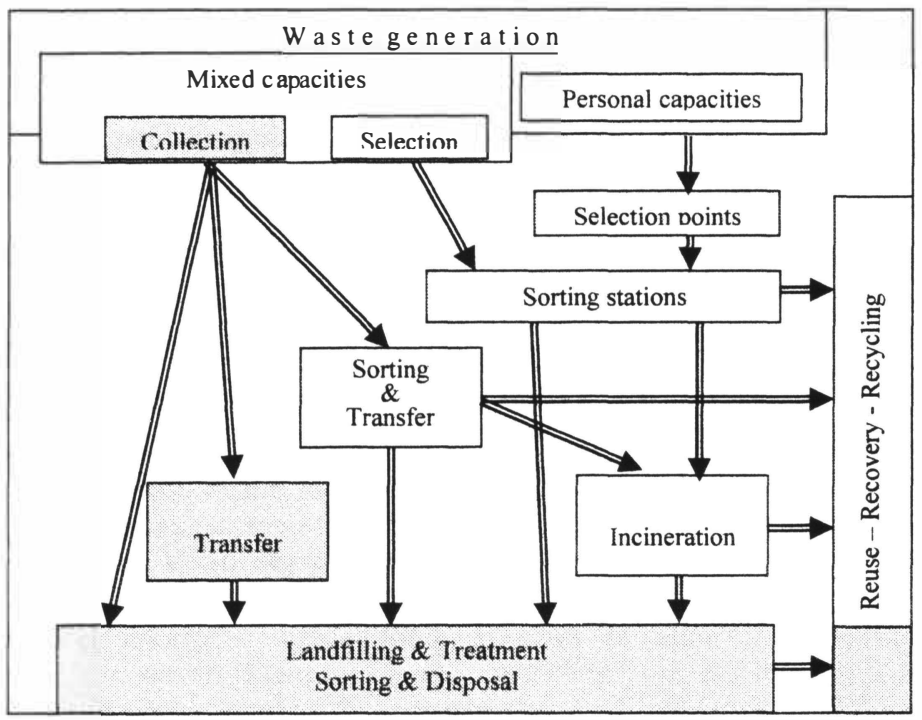

Figure 1. Systems and processes for wastc management in St.-Petersburg. 


\section{ENERGY RECOVERY FROM THE SMW}

In the field of the solid municipal waste there is an actual problem of the technology evaluation basing on its economic and ecological characteristics. Therefore comes in question the necessity of the studies for the technical solutions stability, as the minimization of the costs and the minimization of the impact upon the environment usually contradict each other. The development of the balance between these contradictory aspects complies with the sustainability principles and insures stable environment for the market economy development in the sector. The multi criteria analysis, as the previous studies show, provides the comprehensive modeling better than other techniques. This approach is developed in the model "costs-technological impact" for the case of the balanced fuel composition including waste, natural gas, oil or coal in the municipal heating system.

\subsection{Energy recovery actual development}

The international practice of the energy recovery includes the following methods of the thermal waste processing:

- $\quad$ non-treated waste incineration in power boilers;

- $\quad$ pre-treated waste incineration together with natural gas in power boilers;

- $\quad$ non-treated and pre-treated waste pyrolysis.

Depending on the temperatures used, all the processes of the thermal waste processing are divided into two groups:

- $\quad$ processes with the temperatures lower than slack melting point;

- $\quad$ processes with the temperatures higher than slack melting point.

The main factors determinating the choice of the thermal technology include the composition and qualities of the waste, equipment capacity, capital and operation costs in disposal, effectiveness and security of the process, possibility for the automatization and environmental impact minimization [3].

Some of these factors should be considered as the restrictions of the model. Costs minimization and minimization of the environmental impact, due to their contradictory nature, should be considered as points for optimization.

In regard to the environmental impact of the waste incineration, it is important to note, that the SMW include fractions, which produce hazardous chemical substances, when incinerated. The actual technology allows the usage of the thermal techniques, necessary to destroy the hazardous substances with the parallel usage of the smoke gas filters and the necessary elimination of the solid waste and sewage waters.

\subsection{Model}

The city government of St. Petersburg has initiated the preparation project for the construction of the incineration plant with energy recovery [4]. The preliminary studies include the presented model for energy recovery with cost and risk minimization as the objectives. 


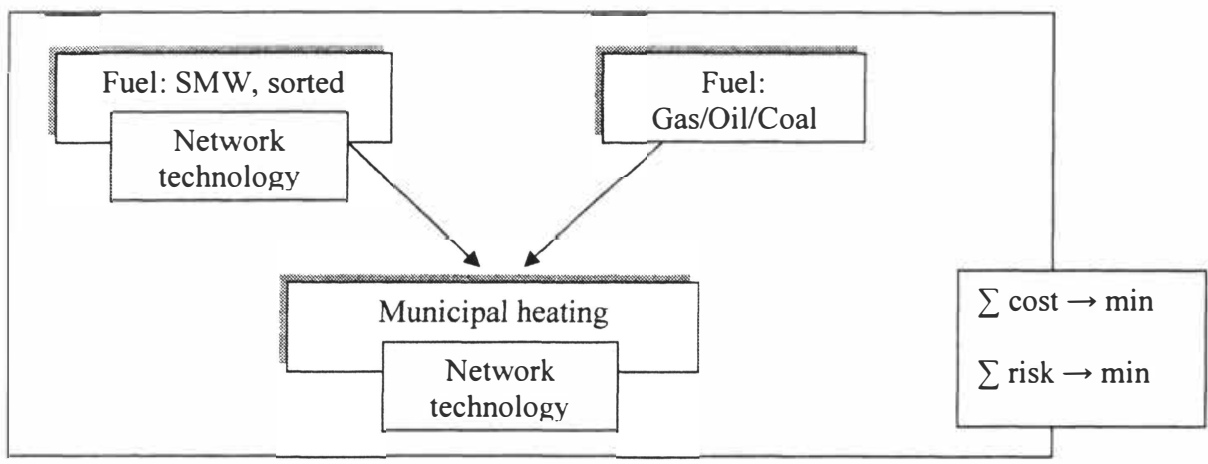

Figure 2. Basic model for energy recovery.

In the model the perspective communal heating system is considered, where the sorted solid municipal waste is used along with the standard fuel.

Ecological parameters to be optimized include technological impact (technological figures), which describes the level of air pollution caused by the fuel incineration. Economic parameters include operation as well as capital expenditures.

The model considers the use of the fuel composition of the sorted SMW and standard fuel options used for the municipal heating.

\subsubsection{Ecological risks}

Ecological risks in this case describe the possible technological impact upon the environment when incinerating fuel of various compositions. Ecological and economic regulation of the gas emissions in the energy sector aims to provide certain frameworks in order to minimize the ecological risks. The basic regulation methods in question are divided in three groups:

[1]. technologic measures, directly polluting the process of the energy production;

[2].seconomic mechanisms for the enforcing and stimulation of the gas emissions minimization at the energy plants;

[3].gas emissions control.

This ranking is also fair in regard of ecological and economic effectiveness of these mechanisms.

The actual state-of-the-art of the monitoring system for air emissions does not guarantee the fast and precise information needed for the effective regulation mechanism for the companies operated in this sector. Therefore, for the modeling purposes it is reasonable to use the analytical instruments, based on the systematic-analytical evaluation and forecasting methods of the potential technological risks.

The basics for the econometric analysis used for the model in question are as follows. The air pollution index (Iт.в) is determined as an indicator for the technological impact of the 
substance upon the environment. It is described as a ratio between its relative hazard and conventional substance, whose maximal concentration permitted, is taken as 1 .

Technological figure (T) is determined as quantitative indicator for the relative ecological risk of the substance. It equals product of the substance mass times its air pollution index.

High toxicology and relatively long remaining time in the air are the reasons for putting together a group of pollutants (see Table 2).

Table 2. Pollution indexes

\begin{tabular}{lcc}
\hline Polluting substance & $\mathrm{MCA}(\mathrm{CC}), \mathrm{mg} / \mathrm{m}^{3}$ & $\mathrm{I}_{\text {T.B }}$ \\
\hline sulfurous anhydride & 0.05 & 20.0 \\
carbon monoxide & 3.0 & 0.33 \\
nitrogen dioxide & 0.04 & 25.0 \\
coal ash & 0.02 & 50.0 \\
oil ash & 0.002 & 500.0 \\
shale ash & 0.1 & 10.0 \\
\hline
\end{tabular}

\subsubsection{Air pollution summarizing principle}

When dealing with the problems of the air pollution of various substances, it is feasible to use a general technological figure, determined as a quantitative indicator for the relative ecological risk for the substances with complicated composition and equals the algebraic sum of the technological figures for each pollutant of the composition.

According to the actual sanitary norms [5], there is a maximum concentration allowed for each of the polluting substance (MCA). When several pollutants are present in the air, for some of them comes in question the summarizing effect. In this case the situation is to be modeled based on the general technological figure. In the same time, the summarized toxicology is to be evaluated based on the actual list of the substances for which the MCA should be taken into account.

This means, that summarizing effect is in reality used for a limited number of the substances only. Therefore it is fair to consider such approach as a preliminary [6].

\subsubsection{Method}

The economic and ecological aspects of the integrated model for the public heating system are considered as objective to be minimized:

$$
\begin{aligned}
& \sum \operatorname{cost}(\mathrm{V}, \mathrm{P}) \rightarrow \min _{(\mathrm{V})} \\
& \sum \operatorname{risk}(\mathrm{V}, \mathrm{E}) \rightarrow \min _{(\mathrm{V})}
\end{aligned}
$$

Where

$\mathrm{V}([\mathrm{V}]=$ tones $)=\mathrm{Vb}, \mathrm{Vs}-$ related amount of bio or standard fuel used, which presents the variables for optimization task: $\min (\mathrm{V})$;

$\mathrm{Pi}$ - fuel costs for each unit and type of fuel, $\mathrm{i}=\mathrm{b}, \mathrm{s}$;

$\mathrm{Ei}$ - general technological figure for the fuel composition pro unit resulted by the incineration of the different types of fuel, $i=b, s$; 
cost $(\mathrm{Vi}, \mathrm{Pi})$ - costs for i-type of fuel;

risk (Vi, Ei) - general technological figure for i-type of fuel.

In the case of the spreaded system (independent aggregates for each type of fuel $i=b, s$ ) the lineal model, e.g. summarized costs and risks optimization, is fair in the frames of the summarization principle.

In the case of the integral system option (fuel composition aggregate for the fuel " $b+s$ ") the lineal model, along with the summarization principle, foresees the "unimportance" of the bio fuel part, which corresponds to the existing experimental result for the gasification technology with cycled boiling layer [7].

\section{CASE STUDY}

The following case study aims to demonstrate the presented model in action. Here several fuel options are tested with amount of each component provided (see Table 1).

Table 1. Fuel options

\begin{tabular}{|c|c|c|}
\hline \multirow[b]{2}{*}{ Fuel Option* } & \multicolumn{2}{|c|}{ Parameters } \\
\hline & $\begin{array}{c}\mathrm{P} \\
\$ / \text { ton }\end{array}$ & $\begin{array}{c}E \\
10^{-6} \mathrm{X} / \text { ton }\end{array}$ \\
\hline $\begin{array}{c}\text { Bio fuel, \#1 } \\
\text { paper + textile } \\
0.8: 0.2 \\
\end{array}$ & 30 & 218 \\
\hline $\begin{array}{c}\text { Bio fuel, \#2 } \\
\text { leather + plastic } \\
0.08: 0.92\end{array}$ & 30 & 266 \\
\hline $\begin{array}{c}\text { Standard fuel, \#1 } \\
\text { gas + oil + coal } \\
0.84: 0.095: 0.065\end{array}$ & 39 & 167 \\
\hline $\begin{array}{c}\text { Standard fuel, \#2 } \\
\text { gas + oil + coal } \\
0.64: 0.07: 0.29\end{array}$ & 36 & 223 \\
\hline $\begin{array}{c}\text { Bio fuel, \#3 } \\
\text { leather + plastic } \\
0.08: 0.92\end{array}$ & 22 & 266 \\
\hline $\begin{array}{c}\text { Standard fuel, \#3 } \\
\text { gas + oil + coal } \\
0.64: 0.07: 0.29\end{array}$ & 39 & 223 \\
\hline
\end{tabular}

The structure $(\mathrm{P}, \mathrm{V}) \rightarrow \mathrm{COST} ;(\mathrm{E}, \mathrm{V}) \rightarrow$ RISK is established with the parameters $\mathrm{P}, \mathrm{E}$ of the multi criteria model for the energy recovery from the sorted solid municipal waste:

the variables of the model ( $\mathrm{V}$ - optimized variables) are set as amount of the waste processed and standard fuel used; 
- the external parameters of the problem: P - poor costs for the various types of fuel (including the prices for the sorted SMW) and poor technological impact upon the environment from fuel incineration - E.

The allocations of fuels are tested for Pareto optimality. The corresponding analysis shows that multi criteria approach can be applied for the evaluation and forecasting of the technological impact of the energy recovery upon the environment (see Figure 4, Figure 5):

- the actual tendencies of the prices increase for the standard fuel create a favorable environment for the use of the solid municipal waste as a fuel (corresponding Pareto optimal $\neq \varnothing$ );

to every point of the Pareto optimal correspond a pair of the parameters (Cost, Risk). According to the econometric methodology, the general technological impact figure in this model (Risk) can be used for the evaluation of the influence upon the environment of the energy recovery from the SWM project.

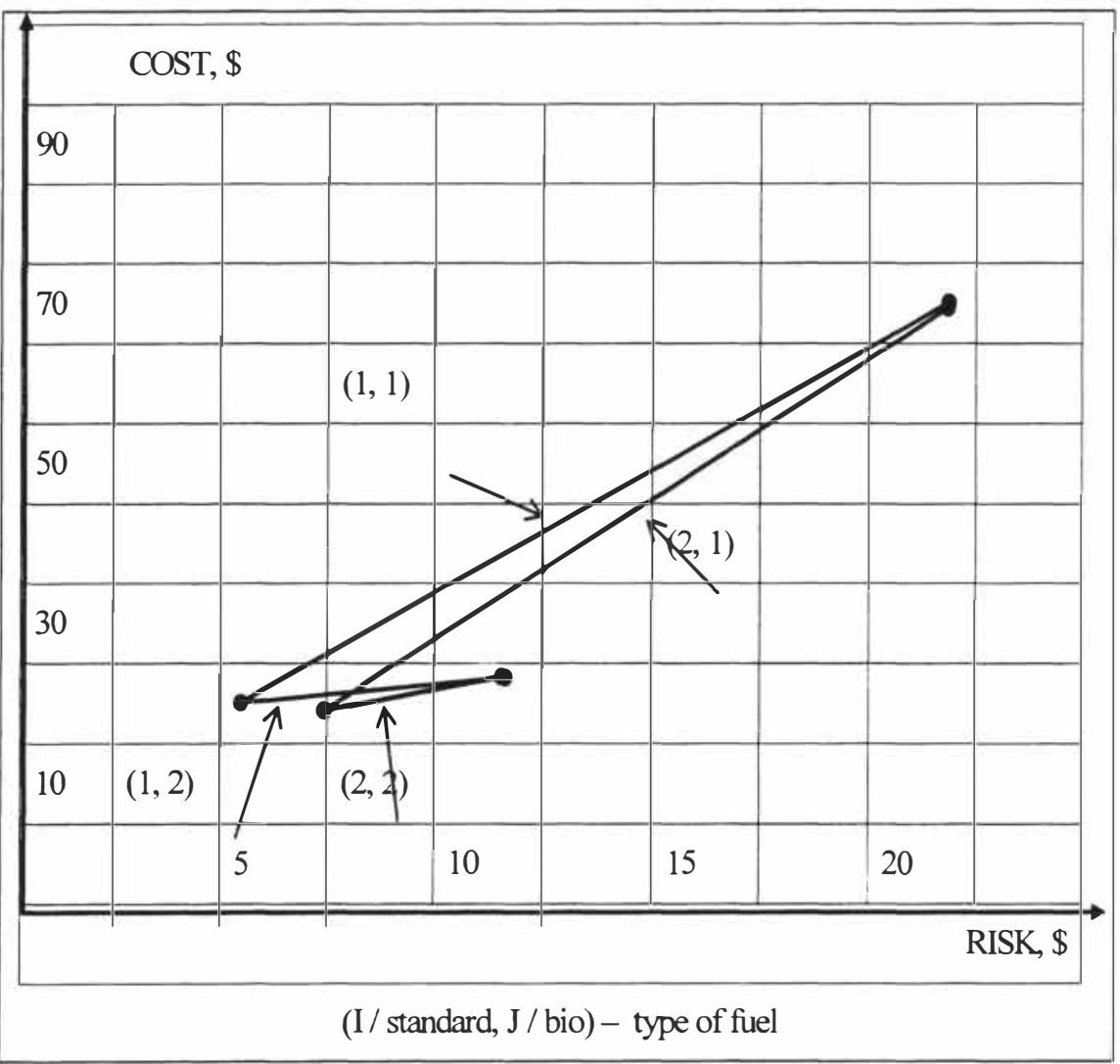

Figure 4. Energy recovery from SMW: multiple choice (basic situation) 
For the fuel options $(1.1),(1.2),(2.1),(2.2)$ the best choice principle allows energy production only from the standard fuel option.

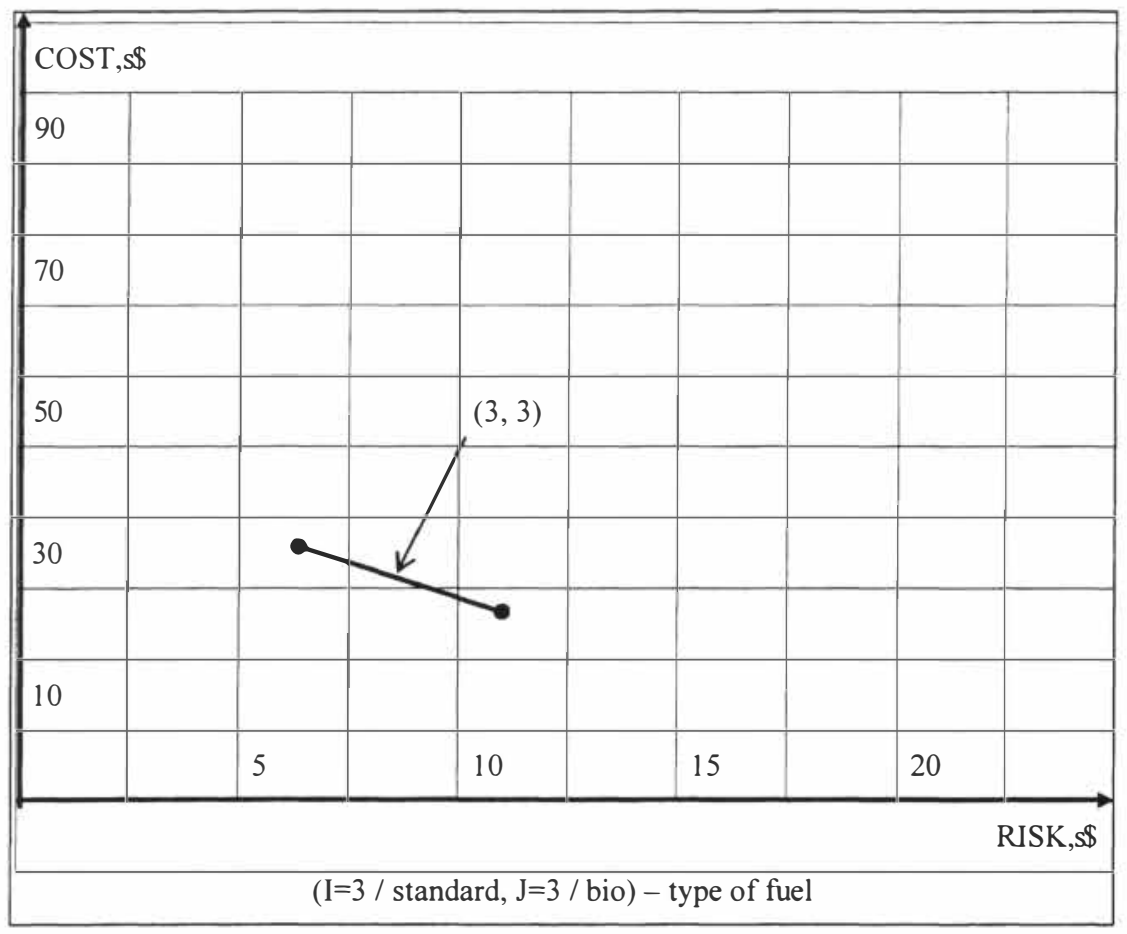

Figure 5. Energy recovery from the SMW: multiple choices (situation in perspective)

For the fuel option (3.3) the best choice principle allows energy recovery from the solid municipal waste.

\section{CONCLUSION}

Indicators for the sustainable development (including ecological, economic, institutional and social aspects) and elements of the multi criteria modeling allow working out a well balanced system for the solid municipal waste management in the city.

However, the further step towards efficient waste management lies in optimizing each technique proposed in the system. In the study presented an optimized balance of the fuel usage in the municipal heating system was developed. Analysis for possible minimization of the economic (costs) and ecological (pollution impact) parameters proved energy recovery from the solid municipal waste as a feasible option. 


\section{REFERENCES}

[1] Institutionalising the Environmental Planning and Management, 1999. Vol. 5, SCP Source Book Series, UN HABITAT/UNEP.

[2] Voronov, A., 2004. Models and methods development for the balanced strategy establishment in the field of the SWM. The Second Finnish-Russian Workshop on Waste Management.

[3] Sister, V., 2003. Modern technologies for the SWM treatment. Moscow, Russia (in Russian).

[4] Waste to energy plant, 2002. State owned company "TEK of St. Petersburg" (in Russian).

[5] Sanitary norms for the industrial plants planning, 1971. SN 245-71. Strojizdat, Moscow, Russia (in Russian).

[6] Recommendations for the summarizing effiects calculation, 1999. Institute for the general and municipal sanitation named after A. N. Sisjin / ed. Yu. Maksimenko (in Russian).

[7] Hoffren H., 2001. Heavy metal emissions from municipal waste and biomass co-firing in bubbling fluidized bed boiler. In: Proceedings of 12th World Clean Air Congress. 